\title{
The Glass-Coated Melt Spinning of Gold Filaments
}

\author{
Tomoko Gotō
}

Department of Fibre and Polymer Technology, Nagoya Institute of Technology, Nagoya, Japan

\section{Fine gold wire for use in the electronics industry is normally die drawn in} a number of stages. The author describes a technique whereby fine filaments of gold, and other metals and alloys, can be produced directly from the molten metal in one stage.

The demand for fine metallic fibres is growing steadily as a result of their increasing use, especially in composite materials and in electronic and electrical equipment. The cold die-drawing process is widely used to satisfy this demand but the cost of fibres produced by this method increases significantly as fibre diameter decreases, thus limiting commercial applications. The forming of filaments directly from molten metal by the Taylor process (1) and by the melt spinning process (2) has therefore been attempted. A difficulty has been that the molten metal tends to evaporate or disintegrate before solidification takes place during the spinning process. A modification of the Taylor process, in which the molten metal is glass-coated during spinning overcomes this problem and has been found effective (3) for the production of metallic filaments less than $50 \mu \mathrm{m}$ in diameter, from copper, silver, iron, stainless-steel and various other metals or alloys.

The apparatus used is shown in Figure 1 . About $1 \mathrm{~g}$ of metal is placed into a glass tube and melted by an induction heating coil. Through interaction between the magnetic field and the induced eddy current, the molten metal can be kept globular and suspended in a fixed position. When the glass tube is drawn, the metal is pulled down with the glass and a glass-coated metallic filament is formed, which can be coiled on a winding drum. The glass tube is automatically fed at a suitable rate and the position of the globule relative to the heating coil is kept fixed as shown in Figure 2. The temperature of the metal is predetermined by the position of the molten globule. Virtually continuous melt spinning of copper, silver and stainless-steel has

Fig. 1 Apparatus developed at the Nagoya Institute of Technology for the production of fine wires by the glasscoated melt spinning method. The machine consists essentially of a glass tube feeding device, an induction coil heater and a winding drum. It is seen here during the production of gold wire

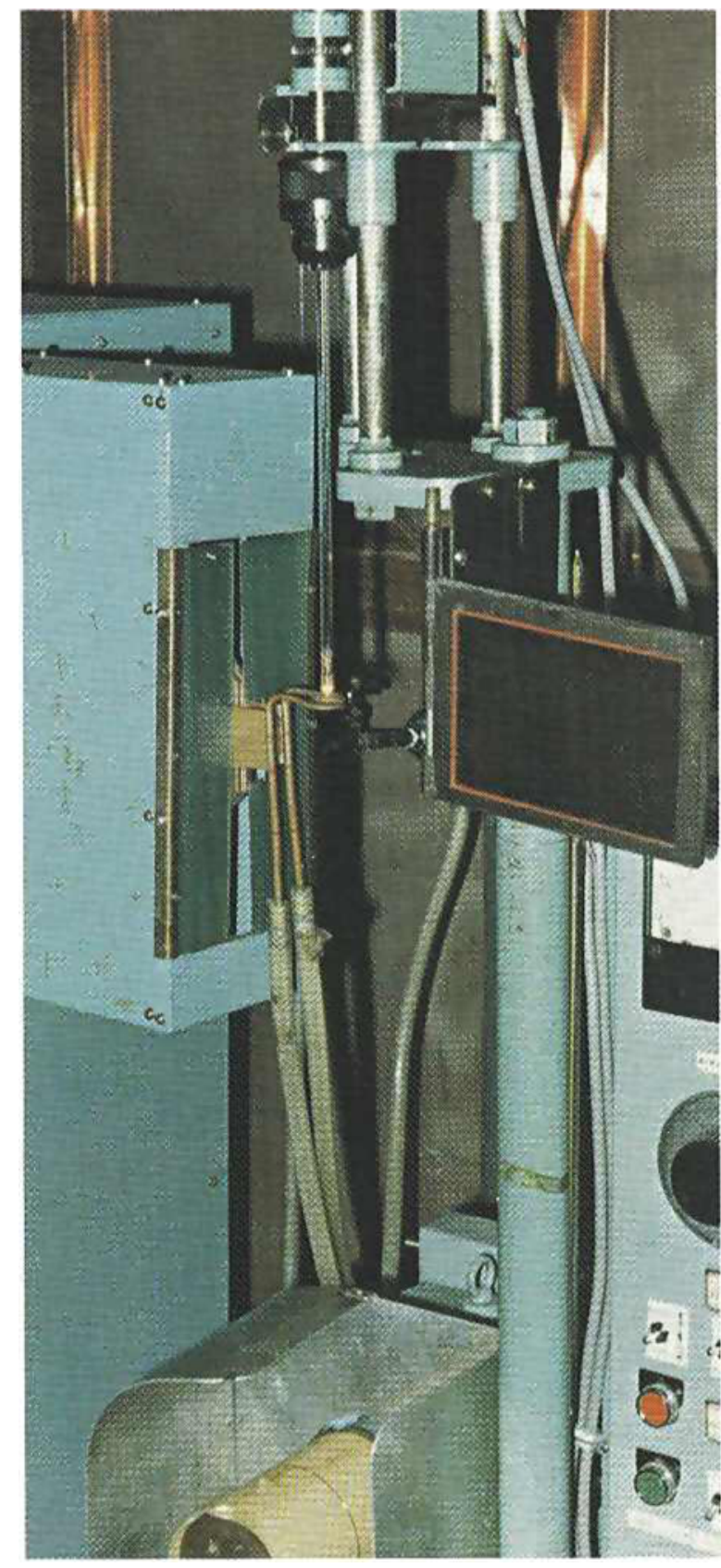


been made possible by taking advantage of the spinnability of pyrex glass (3), the filaments being formed at a cooling rate of more than $10^{5 \circ} \mathrm{C} / \mathrm{s}$ with a reduction of cross-section of about 99.9 per cent.

The melt spinning of gold ( 99.99 per cent purity) has been carried out by the same method as that used for copper (4). Although the density of gold is high and the spinning operation is difficult compared with copper, spinning was successfully conducted from a melt at a temperature of $1200^{\circ} \mathrm{C}$ using winding speeds varying from 57 to $332 \mathrm{~m} / \mathrm{min}$. The glass coating was removed from the wire while it was still coiled on the spool by dissolution in a 45 per cent hydrofluoric acid solution. The diameter of the filaments obtained decreased slightly with increasing speed of winding and ranged from 3 to $13 \mu \mathrm{m}$.

Gold filaments produced in this way are shown in Figure 3. They have smooth surfaces and are free from defects. Several cross-sections of filaments were observed by scanning electron microscopy. In each case the fibres were found to be polycrystalline with a grain size of more than $2000 \AA$. Fibre texture was investigated by $\mathrm{X}$-ray diffraction and double $<111\rangle+<100\rangle$ textures were observed, with the volume fraction of the $\langle 111\rangle$ component increasing with faster winding.

The tensile strength of the gold filament was also measured. A noticeable feature of the stress-strain curves was the high hardening rate, as a result of which a high stress level was reached after an elongation of a few per cent only. The tensile strength increased significantly as the diameter of the filaments decreased.

It is remarkable to note that while bulk pure gold has a tensile strength of $130 \mathrm{MPa}$ with an elongation of 45 per cent, filaments $3.5 \mu \mathrm{m}$ in diameter produced by glass-coated melt spinning were found to have a

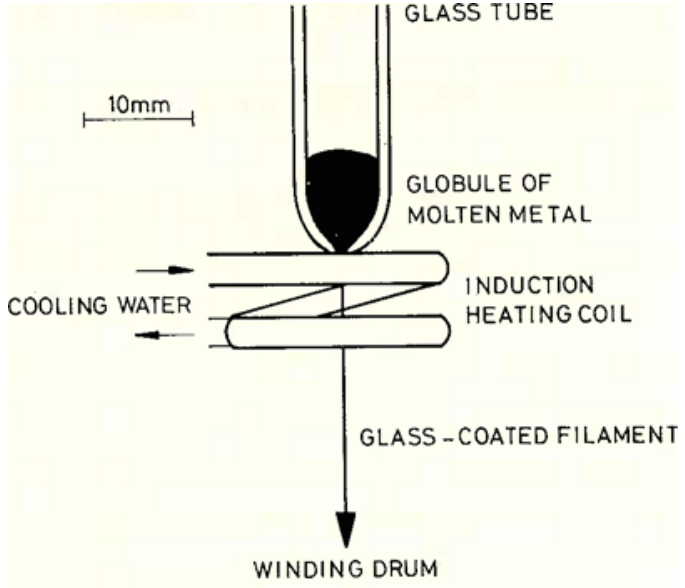

Fig. 2 Diagram of the arrangement used for the glass-coated melt spinning of metals or alloys

tensile strength of $285 \mathrm{MPa}$ and an elongation of 7 per cent. The latter figures are well within the standard requirements for gold wire for semiconductor lead-bonding (5).

It is probable that multi-metallic filaments containing gold could also be produced by the method described above, using a modification of the double bushing techniques which have been described for the manufacture of fibre glass $(6,7)$.

\section{References}

1 G. F. Taylor, Phys. Rev., 1924, 23, 655

2 R. B. Pond, U.S. Patents 2,825,108 and 2,907,082

3 T. Gotōet al., Trans. Ypn. Inst. Met., 1977, 18, 209-213, $557-561,562-566,759-764$, and $1978, \mathbf{1 9}, 60-61$

4 T. Gotō and M. Nagano, 7. Soc. Fiber Sci. Technol. Jpn., 1977 33, T302-T306 (in Japanese)

5 ASTM F72

6 Owens Corning Fibreglass, U.S. Patent 2,693,668 and British Patent 1370906

7 Nippon Selfac K.K., British Patent 1319670
Fig. 3 Scanning electron micrograph of gold filaments spun at $332 \mathrm{~m} / \mathrm{min}$. The surface quality of the product is excellent

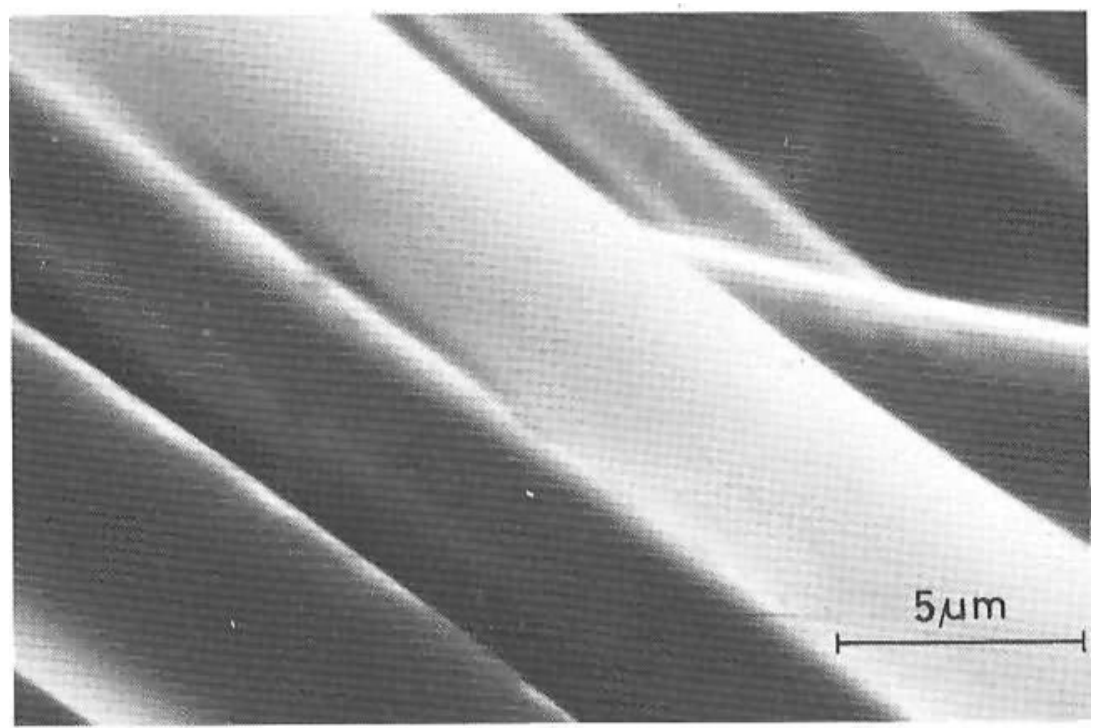

